\title{
Rapid expansion of Greenland's low-permeability ice slabs
}

\author{
M. MacFerrin ${ }^{1 *}$, H. Machguth ${ }^{2,3}$, D. van As ${ }^{4}$, C. Charalampidis ${ }^{4,5}$, C. M. Stevens ${ }^{6}$, A. Heilig ${ }^{7,8,9}$, B. Vandecrux ${ }^{4,10}$, P. L. Langen ${ }^{11}$,
} R. Mottram ${ }^{11}$, X. Fettweis ${ }^{12}$, M. R. Van den Broeke ${ }^{13}$, W. T. Pfeffer ${ }^{14}$, M. Moussavi ${ }^{1,15}$ \& W. Abdalati ${ }^{1}$

In recent decades, meltwater runoff has accelerated to become the dominant mechanism for mass loss in the Greenland ice sheet ${ }^{1-3}$. In Greenland's high-elevation interior, porous snow and firn accumulate; these can absorb surface meltwater and inhibit runoff ${ }^{4}$, but this buffering effect is limited if enough water refreezes near the surface to restrict percolation ${ }^{5,6}$. However, the influence of refreezing on runoff from Greenland remains largely unquantified. Here we use firn cores, radar observations and regional climate models to show that recent increases in meltwater have resulted in the formation of metres-thick, low-permeability 'ice slabs' that have expanded the Greenland ice sheet's total runoff area by $26 \pm 3$ per cent since 2001. Although runoff from the top of ice slabs has added less than one millimetre to global sea-level rise so far, this contribution will grow substantially as ice slabs expand inland in a warming climate. Runoff over ice slabs is set to contribute 7 to 33 millimetres and 17 to 74 millimetres to global sea-level rise by 2100 under moderate- and high-emissions scenarios, respectivelyapproximately double the estimated runoff from Greenland's highelevation interior, as predicted by surface mass balance models without ice slabs. Ice slabs will play an important role in enhancing surface meltwater feedback processes, fundamentally altering the ice sheet's present and future hydrology.

A field campaign carried out in spring 2012 at the KAN_U field site at $1,840 \mathrm{~m}$ above sea level (a.s.l.) in southwest Greenland's accumulation area found 3-5-m-thick layers of refrozen meltwater in firn cores just below the seasonal snow layer ${ }^{5,6}$. The record-breaking 2012 Greenland summer melt ${ }^{7,8}$ caused meltwater to visibly run off from KAN_U over the top of these layers for the first time on record instead of refreezing locally in porous firn. Thick ice layers resulted in approximately $11 \pm 3 \%$ more runoff in that region than would have occurred without the blocking effect of subsurface ice ${ }^{5}$.

The Spring 2013 Arctic Circle Traverse (ACT-13) campaign in southwest Greenland mapped a continuous 40-km-long, multimetre-thick ice slab along an uphill transect in southwest Greenland (Fig. 1). Runoff was routed over the top of this slab instead of being fully absorbed into the firn column. During the 2012 summer, the equilibrium line altitude, where annual melt equals accumulation, was estimated to be approximately $1,900 \mathrm{~m}$ a.s.l.

In this work we distinguish between ice lenses and ice slabs in firn. Ice lenses are thin $(0-10 \mathrm{~cm})$ refrozen ice layers that form in a single melt season in the percolation area of the ice sheet ${ }^{9,10}$. Meltwater can percolate through and around lenses ${ }^{11}$ along preferential flow paths, sometimes reaching depths of $10 \mathrm{~m}$ or more before refreezing ${ }^{12}$. Layers of refrozen ice between $10 \mathrm{~cm}$ and $1 \mathrm{~m}$ thick-primarily multi-annual refreezing features-were documented in $2016^{11}$ in cores and deep pits in southwest Greenland's percolation area up to an altitude of 2,100 m a.s.l., but their horizontal extent appeared limited and not able to cause runoff over wide areas. Low-permeability ice slabs are thicker refrozen layers ( $\geq 1 \mathrm{~m}$ thick) that form when water refreezes between preexisting ice layers, annealing them together. Slabs form over several years, can span horizontally for tens of kilometres and cause the permeability of the near-surface firn layer to approach zero ${ }^{13}$ despite pore space availability at greater depth. Ice slabs are spatially continuous enough to be mapped over great distances by ground-penetrating radar surveys. Here we focus solely on ice slabs in Greenland's firn that block deep percolation and enhance runoff.

We present an observational map of ice slabs across the Greenland ice sheet, created from surveys performed by the ground-penetrating radar (GPR) and NASA's IceBridge airborne Accumulation Radar (IceBridge AR), and validated against firn cores drilled along the GPR surveys. We use an empirical model to quantify the present-day formation of ice slabs from the outputs of regional climate models (RCMs). Using RCMs forced on their boundaries by forward-looking general circulation models (GCMs), we forecast the growth of ice slabs and their contributions to runoff under the Representative Concentration Pathway (RCP) 4.5 and 8.5 (moderate- and high-emissions, respectively) scenarios through the end of the 21 st century.

Shallow firn cores retrieved along the ACT-13 transect contain $\geq 1$-m-thick ice slabs at sites below 2,000 $\mathrm{m}$ a.s.l. (Extended Data Fig. 1a, cores 1-3, and Extended Data Fig. 2$)^{5}$. Ice slabs at KAN_U have grown progressively thicker; in five years, the ice volume content of the top $10 \mathrm{~m}$ grew from $54 \%$ in 2012 to $73 \%$ in 2017 (Extended Data Fig. 1b), with nearby locations experiencing similar growth (Extended Data Fig. 1c).

In situ GPR measurements show ice slabs beginning at approximately $1,700 \mathrm{~m}$ a.s.l. along the ACT-13 transect (Fig. 1b), indicating that in 2012 the long-term runoff limit had migrated up to the KAN_U site at $1,840 \mathrm{~m}$ a.s.l., consistent with satellite observations ${ }^{5}$. Ice slabs detected from a spatially coincident transect of IceBridge AR, flown three weeks before the ACT- 13 transect, closely match results in the top $20 \mathrm{~m}$ of firn with a vertical error of $-21 \%$ to $+6 \%$ compared to adjacent cores, partially underestimating the ice volume but accurately measuring the overall extent of ice slabs within the top $20 \mathrm{~m}$ of firn. A survey of IceBridge AR flight lines from 2010-2014 (Fig. 2) show that ice slabs covered $64,800-69,400 \mathrm{~km}^{2}$ of the Greenland ice sheet in 2014, or approximately $4 \%$ of the ice sheet's total area. We identify ice slabs as continuous layers of near-surface ice above porous layers of firn; they have a thickness of $1-16 \mathrm{~m}$ in the top $20 \mathrm{~m}$ of firn and extend continuously for $\geq 1 \mathrm{~km}$ along an IceBridge flight line. We adjust the thickness observations of IceBridge AR according to the range of thickness uncertainties, map spatially continuous slabs of 1-16 m thickness and interpolate polygons around continuous areas of ice slabs to estimate

${ }^{1}$ Cooperative Institute for Research in Environmental Sciences, University of Colorado, Boulder, CO, USA. ${ }^{2}$ Department of Geography, University of Zurich, Zurich, Switzerland. ${ }^{3}$ Department of Geosciences, University of Fribourg, Fribourg, Switzerland. ${ }^{4}$ Geological Survey of Denmark and Greenland, Copenhagen, Denmark. ${ }^{5}$ Bavarian Academy of Sciences and Humanities, Munich, Germany. ${ }^{6}$ Department of Earth and Space Sciences, University of Washington, Seattle, WA, USA. ${ }^{7}$ WSL Institute for Snow and Avalanche Research SLF, Davos Dorf, Switzerland. ${ }^{8}$ Department of Earth and Environmental Sciences, Ludwig-Maximilians-University of Munich, Munich, Germany. ${ }^{9}$ Alfred Wegener Institute Helmholtz-Centre for Polar and Marine Research, Bremerhaven, Germany. ${ }^{10}$ Department of Civil Engineering, Technical University of Denmark, Kongens Lyngby, Denmark. ${ }^{11}$ Danish Meteorological Institute, Copenhagen, Denmark. ${ }^{12}$ Department of Geography, University of Liège, Liège, Belgium. ${ }^{13}$ Institute for Marine and Atmospheric Research, Utrecht University, Utrecht, The Netherlands. ${ }^{14}$ Department of Civil Engineering, University of Colorado, Boulder, CO, USA. ${ }^{15}$ National Snow and Ice Data Center, University of Colorado, Boulder, CO, USA. *e-mail: michael.macferrin@colorado.edu 


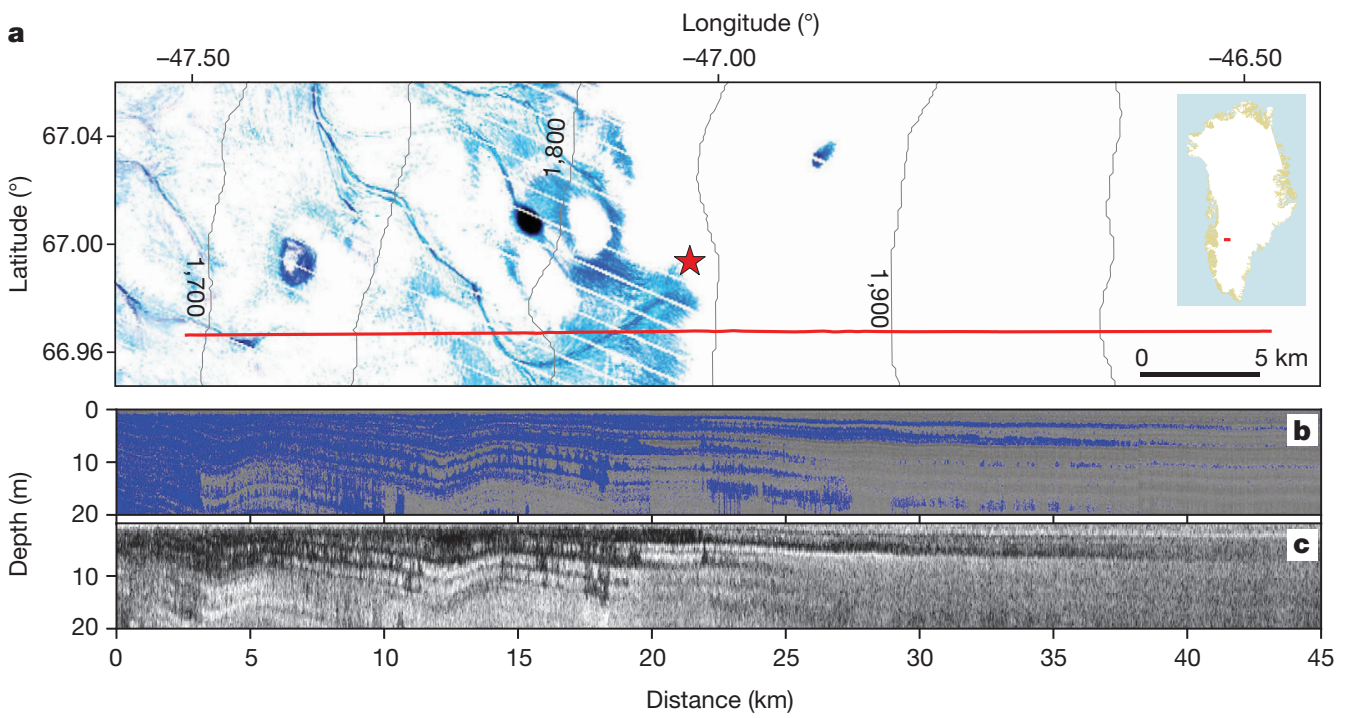

Fig. 1 Meltwater runoff over low-permeability ice slabs in southwest Greenland. a, ACT-13 transect path (red line) overlaid on a LandSat-7 image from 16 July 2012 (contrast-enhanced to show surface water in blue). KAN_U is noted with the red star. 50-m contours from the Arctic Digital Elevation Model (ArcticDEM release 7$)^{31}$ are shown, and elevations are in metres above sea level. b, Data obtained with the 800 $\mathrm{MHz}$ GPR during the ACT- 13 campaign, showing depths of 0-20 m. Layers of refrozen ice are coloured blue. c, Data from a 2013 transect of 550-900 MHz IceBridge AR over the same line, showing depths of 0-20 m. their area. Potential gaps in airborne data coverage make this range a conservative estimate of the total extent of ice slabs in Greenland.

RCMs forced at their boundaries by atmospheric reanalysis data (see Methods) at the locations where IceBridge AR has observed ice slabs suggest that ice slabs occur where annual snow accumulation is below $572 \pm 32 \mathrm{~mm}$ water equivalent (w.e.). Ice slabs appear to be absent in regions of high accumulation in which surface meltwater is trapped in perennial firn aquifers instead of refreezing ${ }^{14,15}$; this is consistent with firn models showing aquifers that form in regions with annual accumulation rates exceeding about $600 \mathrm{~mm}$ w.e. ${ }^{16}$.

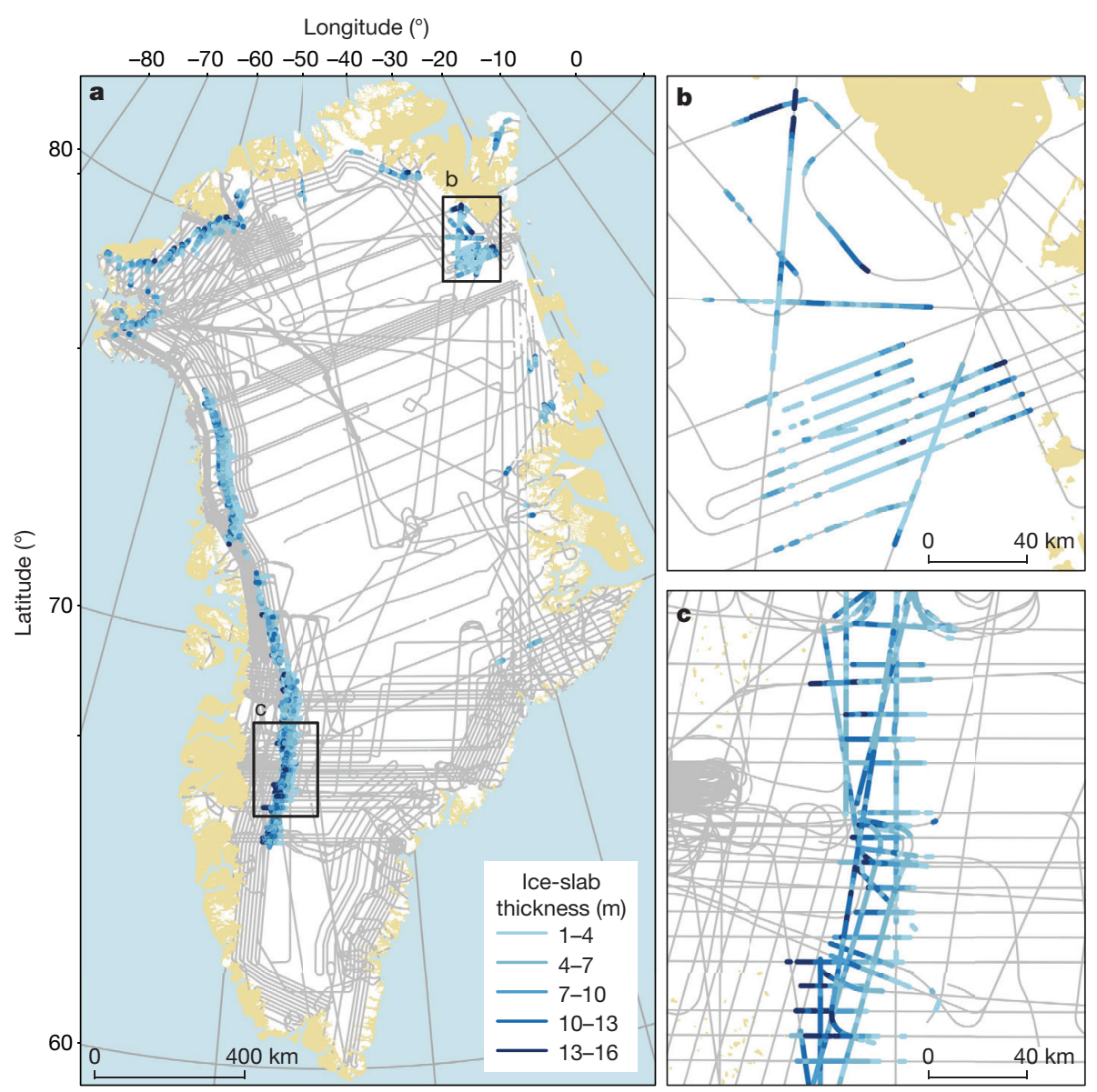

Fig. 2 Low-permeability ice slabs on the Greenland ice sheet and peripheral ice caps detected by IceBridge AR (2010-2014). a-c, Ice slabs detected in Greenland with $-21 \%$ to $+6 \%$ thickness uncertainty. b, c, Zoom-ins $(6 \times)$ on northeast (b) and southwest (c) Greenland. 
Table 1 | RCM results for ice slab growth and runoff

\begin{tabular}{|c|c|c|c|c|c|c|c|c|c|c|}
\hline RCM, forcing & $\begin{array}{l}\text { Area trend } \\
\left(\mathrm{km}^{2} \mathrm{yr}^{-1}\right)\end{array}$ & $\begin{array}{l}\text { Total area } \\
\left(\mathrm{km}^{2}\right)\end{array}$ & $\begin{array}{l}\text { Runoff trend } \\
\left(G y^{-1}\right)\end{array}$ & $\begin{array}{l}\text { Runoff acceleration } \\
\left(\text { Gt } \mathrm{yr}^{-2}\right)\end{array}$ & $\begin{array}{l}\text { Total runoff } \\
\text { (Gt) }\end{array}$ & $\begin{array}{l}\text { Area trend } \\
\left(\mathrm{km}^{2} \mathrm{yr}^{-1}\right)\end{array}$ & $\begin{array}{l}\text { Total area } \\
\left(\mathrm{km}^{2}\right)\end{array}$ & $\begin{array}{l}\text { Runoff trend } \\
\left(G_{t} \mathrm{yr}^{-1}\right)\end{array}$ & $\begin{array}{l}\text { Runoff acceleration } \\
\left(\mathrm{Gtt}_{\mathrm{yr}}^{-2}\right)\end{array}$ & $\begin{array}{l}\text { Total runoff } \\
\text { (Gt) }\end{array}$ \\
\hline HIRHAM 5, ERA-Int. & 234 & 2,500 & 0.099 & 0.055 & 1.42 & 5,540 & 67,500 & 13.7 & 2.28 & 166 \\
\hline MAR 3.5.2, NCEP v1 & 53.3 & 491 & 0.025 & 0.013 & 0.35 & 5,300 & 62,100 & 12.5 & 2.48 & 153 \\
\hline RACMO 2.3, ERA-Int. & 330 & 3,310 & 0.209 & 0.070 & 2.35 & 6,310 & 78,900 & 16.2 & 2.74 & 200 \\
\hline MAR 3.5.2, NorESM 1 & 1,280 & 85,400 & 11.9 & 0.698 & 822 & 945 & 135,000 & 66.4 & 0.432 & 3,970 \\
\hline MAR 3.5.2, MIROC 5 & 1,980 & 108,000 & 21.6 & 0.957 & 1,330 & 1200 & 170,000 & 66.0 & 0.834 & 4,570 \\
\hline MAR 3.5.2, CanESM 2 & 3,520 & 205,000 & 59.5 & 2.51 & 3,660 & 762 & 258,000 & 166 & 1.03 & 12,000 \\
\hline RACMO 2.1, HadGEM $2^{\mathrm{b}}$ & 3,970 & 216,000 & 46.5 & 1.96 & 2,810 & 3,095 & 344,000 & 172 & 2.35 & 11,000 \\
\hline 21st century RCP 8.5 & $1990-2050$ & 2050 & 1990-2050 & $1990-2050$ & 2050 & $2051-2100$ & 2100 & $2051-2100$ & 2051-2100 & 2100 \\
\hline MAR 3.5.2, CanESM 2 & 4,160 & 243,000 & 67.3 & 3.13 & 4,250 & 7,130 & 610,000 & 440 & 12.9 & 26,600 \\
\hline
\end{tabular}

Historical results from 1990-2013; 21st century results from 1990-2100.

aHIRHAM 5 21st-century model results only available in three periods: 2000-2010, 2040-2050 and 2090-2100. The 1900-2050 results are computed using 2000-2010 and 2040-2050 combined data with gaps interpolated. The 2051-2100 results are computed using 2041-2050 and 2090-2100 combined data.

bRACMO 2.121 st-century model results conclude in 2098. The 2050-2100 results are computed from 2051-2098 data. RACMO 2.1 results are only available for RCP 4.5, which are included here but not in the moderate-versus-high-emissions visual comparison in Fig. 3.

RCMs forced at their boundaries by atmospheric reanalysis data show that ice slabs have formed in regions receiving $266-573 \mathrm{~mm}$ w.e. $\mathrm{yr}^{-1}$ excess melt for a decade or more (Supplementary Information Fig. 16). Here, 'excess melt' refers to the amount of meltwater beyond the capacity of annual accumulation to absorb and refreeze it, resulting in excess water, which fills surrounding firn layers or runs off to lower elevations (see Methods). In ten years, the upper value of that range $\left(573 \mathrm{~mm}\right.$ w.e. $\mathrm{yr}^{-1}$ ) would transform a shallow porous firn layer (density of 450-550 $\mathrm{kg} \mathrm{m}^{-3}$ ) into refrozen ice with bubbles (density of $873 \mathrm{~kg} \mathrm{~m}^{-3}$ ) to a thickness of 13.6-17.7 m, in agreement with the maximum-thickness threshold of $16 \mathrm{~m}$ used when detecting ice slabs with IceBridge AR. RCMs show that in data pixels containing ice slabs detected by IceBridge AR, excess melt increased slowly since the 1990s (Extended Data Fig. 3) and then rapidly after 2001, causing the inferred annual rates of ice slab formation to increase ten times or more (Table 1, Fig. 3a). At the end of 2013, RCMs estimate that ice slabs in Greenland covered an area 62,100-78,900 km2 larger than Greenland's pre-1990 runoff area. Maps of simulated ice slabs at the end of 2013 (Fig. 3b-e) are consistent with one another, as well as with the extent observed by IceBridge AR (Fig. 2). Within individual ice-sheet drainage basins, simulated ice slab elevations match within uncertainties in nearly every case (Extended Data Fig. 4). Inconsistencies between observed and simulated ice slabs exist primarily in east and southeast Greenland, where ice slabs are limited to relatively small and isolated areas that are difficult to cover fully by airborne IceBridge AR campaigns.

RCMs forced by GCMs until 2100 show that the area of ice slabs across Greenland is likely to expand moderately through 2050 under both RCP 4.5 (Fig. 3f) and RCP 8.5 (Fig. 31) forcing, approximately doubling in area compared to its present extent. Models forced by RCP 4.5 show a relative slowdown of growth in ice slab extent after 2050 through 2100 (Fig. 3f). Most ice slab simulations forced by GCMs underestimate the current extent of ice slabs when compared to reanalysis-forced RCMs (Fig. 3a), in part because present-day GCMs do not capture atmospheric circulation changes over Greenland that have contributed to recent summer melt increases ${ }^{17}$. Under the RCP 8.5 scenario, the formation of new ice slabs accelerates from their 19902050 growth $\left(1,240-4,160 \mathrm{~km}^{2} \mathrm{yr}^{-1}\right)$ to approximately double that rate $\left(2,890-7,130 \mathrm{~km}^{2} \mathrm{yr}^{-1}\right)$ in the latter half of the century (Fig. 3l, Table 1). In all cases, trends before and after 2050 trends are statistically significant $(P<0.02)$.
In 1990-2100, ice slabs are expected to cover 2.3 times larger area and cause 2.4 times more surface runoff, on average, under the RCP 8.5 pathway than under RCP 4.5. Once ice slabs have formed, runoff is calculated as the amount of melt that exceeds the near-surface pore space and the cold content that have accumulated since the ice slabs initially formed (see Methods). Without explicitly handling the effects of ice slabs, by 2100 RCMs underestimate the cumulative runoff from areas that are above the pre-1990 runoff area by an average of $56 \%$ under RCP 4.5 and $42 \%$ under RCP 8.5, compared to equivalent estimates including ice slabs. In both scenarios, this implies a near-doubling of runoff from the interior of the ice sheet due to rapidly decreased surface porosity.

Polar firn is sensitive to relatively small changes in annual meltwater production ${ }^{18,19}$, and the addition of large areas of new ice slabs in Greenland is indicative of a departure from steady-state climate that amplifies several types of positive-mass-loss feedback. For instance, meltwater saturation of the ice-sheet surface at KAN_U in 2012 resulted in $9 \%$ lower summer albedo and the absorption of $28 \%$ additional solar radiation, of which $71 \%$ was translated into melt ${ }^{20}$. This melt-albedo feedback is not fully captured in the RCMs presented here, so future meltwater estimates may be underestimated. Under linear warming conditions, step changes in runoff elevation cover increasingly larger areas of the ice sheet's flat interior ${ }^{6}$, resulting in parabolic increases in runoff area (parabolic fit with a power of $\sim 2.5$ with respect to elevation) and runoff volume (power of $\sim 3.5)^{21}$.

Surface features such as firn cracks, supraglacial streams, lakes and moulins are important components of the ice sheet's hydrological network $^{22}$. The amount of recent meltwater in Greenland has been unprecedented over the past several centuries ${ }^{23}$ and is expected to keep rising in a warming climate, forming supraglacial lakes and other features progressively higher on the ice sheet ${ }^{24}$. It is uncertain whether such features at high elevations could facilitate water reaching the englacial or subglacial system ${ }^{25}$, which is a necessary condition for dynamic feedback processes such as cryo-hydrologic warming ${ }^{26}$ or meltwater reaching previously frozen regions of the ice-sheet bed ${ }^{27}$. However, recent observations of ice motion at KAN_U show accelerated flow in 2009-2013 and seasonal accelerations that were previously unseen at that elevation ${ }^{28}$. Although the exact mechanisms of such dynamic feedback processes are beyond the scope of this paper, they are consistent with meltwater saturation at the same locations and suggest that one 

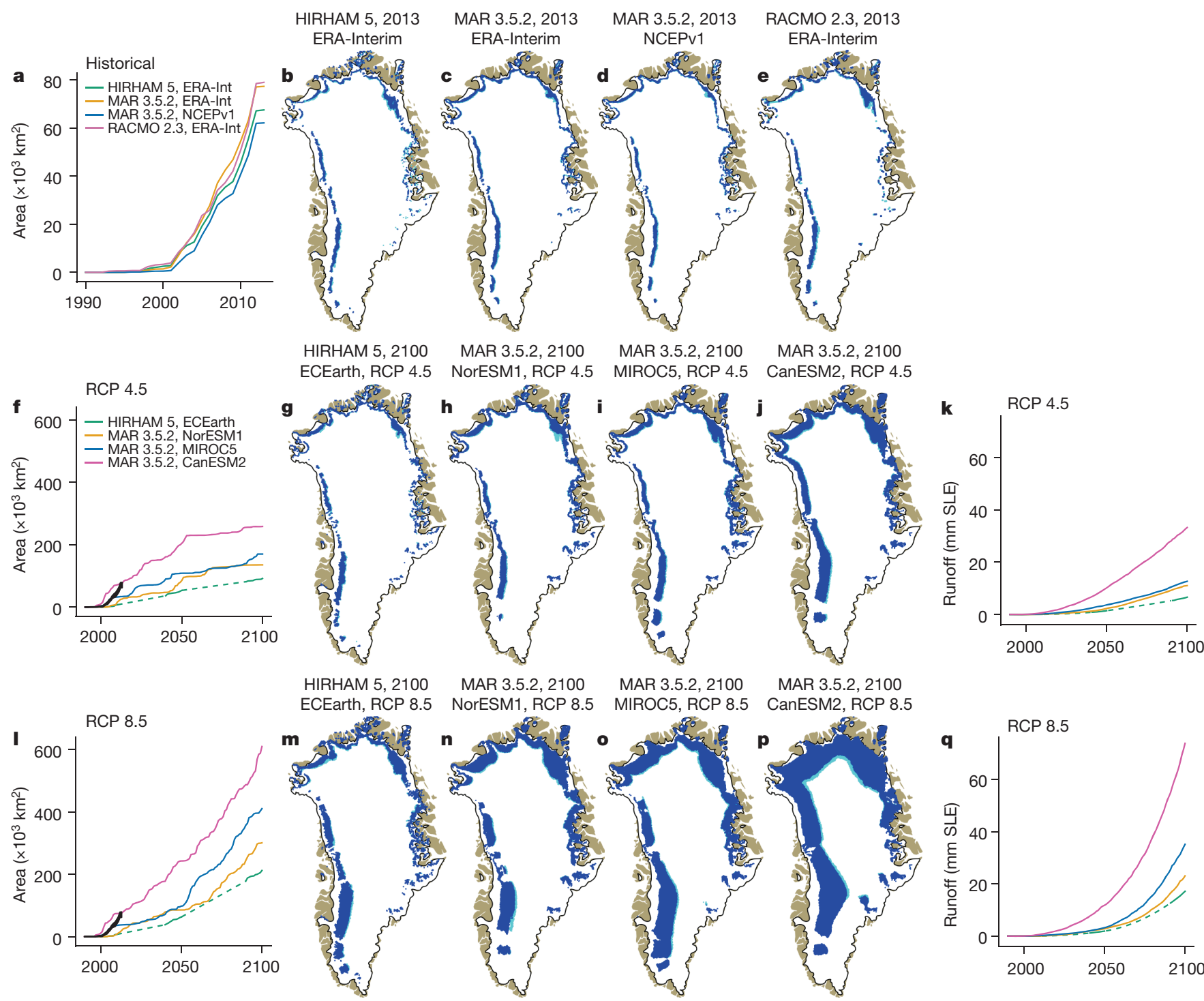

MAR 3.5.2, 2100

MIROC5, RCP 8.5 CanESM2, RCP 8.5

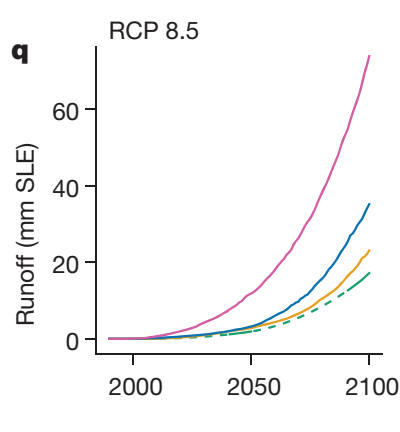

Fig. 3 Ice slab growth and runoff computed by outputs from RCMs. a-e, RCMs forced by reanalysis datasets (see key in a) through 2013, directly comparable to the ice slab observations shown in Fig. 2. $\mathbf{f}-\mathbf{q}, 21$ st-century RCM results forced by GCMs (see key in $\mathbf{f}$ ) under the RCP $4.5(\mathbf{f}-\mathbf{k})$ and $8.5(\mathbf{l}-\mathbf{q})$ pathways. The black line in $\mathbf{f}$ and $\mathbf{l}$ represents the historical ice slab growth from a for comparison. Runoff estimates in $\mathbf{k}$ and $\mathbf{q}$ show 21st-century runoff in global sea-level-equivalent (SLE)

or more meltwater-dynamic feedback processes may already influence dynamic flow at the current locations of ice slabs. Further research is needed to explore the feedback between the hydrologic and dynamic systems of the Greenland ice sheet at high elevations.

Once ice slabs have formed, they need relatively small amounts of meltwater to sustain themselves. Following the extraordinary melt years of 2010 and 2012 in southwest Greenland, melt was more moderate in 2013-2017 (ref. ${ }^{29}$ ), although still greater than the 1949-2017 average $^{30}$. Ice slabs continued to grow in thickness in 2013-2017, with new ice freezing atop them, and little to no pore space added to the firn column (Extended Data Fig. 1b). Once low-permeability ice slabs have formed, the only known effective mechanism to eliminate their impact on saturation and runoff is a prolonged period of cooler climate or higher snow accumulation that would allow pore space to reaccumulate at the surface ${ }^{19}$. The fact that ice slabs have continued to thicken and remain close to the surface once they have formed leaves these areas highly vulnerable to enhanced runoff in subsequent warm summers. In a progressively warming Arctic, ice slabs in Greenland's interior are poised to become increasingly widespread persistent features,
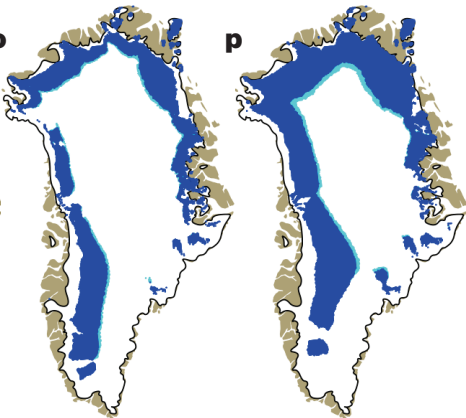

from the top of ice slab regions and do not include contributions from Greenland's historical runoff area. In the maps $(\mathbf{b}-\mathbf{e}, \mathbf{g}-\mathbf{j}, \mathbf{m}-\mathbf{p})$, headings indicate the RCM, year, reanalysis or GCM boundary dataset, and (for the future projections in $\mathbf{g}-\mathbf{j}$ and $\mathbf{m}-\mathbf{p}$ ) the RCP pathway. Dark blue areas are continuous ice slabs that can affect runoff and light blue are intermittent ice slabs that do not yet cause runoff. Only continuous ice slabs (dark blue) are included in trend lines.

with far-reaching consequences for ice-sheet hydrology, runoff and sea level rise.

\section{Online content}

Any methods, additional references, Nature Research reporting summaries, source data, extended data, supplementary information, acknowledgements, peer review information; details of author contributions and competing interests; and statements of data and code availability are available at https://doi.org/10.1038/s41586-019-1550-3.

Received: 12 October 2018; Accepted: 8 July 2019;

1. van den Broeke, M. R et al. On the recent contribution of the Greenland ice sheet to sea level change. Cryosphere 10, 1933-1946 (2016).

2. Fettweis, X. et al. Reconstructions of the 1900-2015 Greenland ice sheet surface mass balance using the regional climate MAR model. Cryosphere $\mathbf{1 1}$ 1015-1033 (2017)

3. Mottram, R. et al. An integrated view of Greenland ice sheet mass changes based on models and satellite observations. Remote Sens. 11, 1407 (2019).

4. Harper, J., Humphrey, N., Pfeffer, W. T., Brown, J. \& Fettweis, X. Greenland ice-sheet contribution to sea-level rise buffered by meltwater storage in firn. Nature 491, 240-243 (2012). 
5. Machguth, $\mathrm{H}$. et al. Greenland meltwater storage in firn limited by near-surface ice formation. Nat. Clim. Chang. 6, 390-393 (2016).

6. Mikkelsen, A. B. et al. Extraordinary runoff from the Greenland ice sheet in 2012 amplified by hypsometry and depleted firn retention. Cryosphere $\mathbf{1 0}$ 1147-1159 (2016)

7. Nghiem, S. V. et al. The extreme melt across the Greenland ice sheet in 2012. Geophys. Res. Lett. 39, L20502 (2012)

8. Tedesco, M. et al. Evidence and analysis of 2012 Greenland records from spaceborne observations, a regional climate model and reanalysis data. Cryosphere 7, 615-630 (2013).

9. Benson, C. S. Stratigraphic Studies in the Snow and Firn of the Greenland Ice Sheet. Research Report No. 70 (US Army Snow, Ice and Permafrost Research Establishment, 1962).

10. Brown, J., Harper, J., Pfeffer, W. T., Humphrey, N. \& Bradford, J. High-resolution study of layering within the percolation and soaked facies of the Greenland ice sheet. Ann. Glaciol. 52, 35-42 (2011)

11. Heilig, A., Eisen, O., MacFerrin, M., Tedesco, M. \& Fettweis, X. Seasonal monitoring of melt and accumulation within the deep percolation zone of the Greenland Ice Sheet and comparison with simulations of regional climate modeling. Cryosphere 12, 1851-1866 (2018).

12. Humphrey, N. F., Harper, J. T. \& Pfeffer, W. T. Thermal tracking of meltwater retention in Greenland's accumulation area. J. Geophys. Res. 117, F01010 (2012).

13. Sommers, A. N. et al. Inferring firn permeability from pneumatic testing: a case study on the Greenland ice sheet. Front. Earth Sci. 5, 20 (2017).

14. Forster, R. R. et al. Extensive liquid meltwater storage in firn within the Greenland ice sheet. Nat. Geosci. 7, 95-98 (2014).

15. Miège, $\mathrm{C}$. et al. Spatial extent and temporal variability of Greenland firn aquifers detected by ground and airborne radars. JGR Earth Surf. 121, 2381-2398 (2016).

16. Munneke, P. K. M., Ligtenberg, S. R., van den Broeke, M. R., van Angelen, J. H. \& Forster, R. R. Explaining the presence of perennial liquid water bodies in the firn of the Greenland Ice Sheet. Geophys. Res. Lett. 41, 476-483 (2014).

17. Hanna, E., Fettweis, X. \& Hall, R. J. Recent changes in summer Greenland blocking captured by none of the CMIP5 models. Cryosphere 12, 3287-3292 (2018).

18. Pfeffer, W. T., Meier, M. F. \& Illangasekare, T. H. Retention of Greenland runoff by refreezing: implications for projected future sea level change. J. Geophys. Res. 96, 22117-22124 (1991).
19. Braithwaite, R. J., Laternser, M. \& Pfeffer, W. T. Variations of near-surface firn density in the lower accumulation area of the Greenland ice sheet, Pâkitsoq, West Greenland. J. Glaciol. 40, 477-485 (1994).

20. Charalampidis, C. et al. Changing surface-atmosphere energy exchange and refreezing capacity of the lower accumulation area, West Greenland. Cryosphere 9, 2163-2181 (2015)

21. van As, D. et al. Hypsometric amplification and routing moderation of Greenland ice sheet meltwater release. Cryosphere 11, 1371-1386 (2017).

22. Rennermalm, A. K. et al. Evidence of meltwater retention within the Greenland ice sheet. Cryosphere 7, 1433-1445 (2013).

23. Trusel, L. D. et al. Nonlinear rise in Greenland runoff in response to postindustrial Arctic warming. Nature 564, 104-108 (2018).

24. Fitzpatrick, A. A. W. et al. A decade (2002-2012) of supraglacial lake volume estimates across Russell Glacier, West Greenland. Cryosphere 8, 107-121 (2014).

25. Poinar, K. et al. Limits to future expansion of surface-melt-enhanced ice flow into the interior of western Greenland. Geophys. Res. Lett. 42, 1800-1807 (2015).

26. Phillips, T., Rajaram, H. \& Steffen, K. Cryo-hydrologic warming: a potential mechanism for rapid thermal response of ice sheets. Geophys. Res. Lett. 37, L20503 (2010).

27. MacGregor, J. A et al. A synthesis of the basal thermal state of the Greenland Ice Sheet. J. Geophys. Res. Earth Surf. 121, 1328-1350 (2016).

28. Doyle, S. H. et al. Persistent flow acceleration within the interior of the Greenland Ice Sheet. Geophys. Res. Lett. 41, 899-905 (2014).

29. Bevis, M. et al. Accelerating changes in ice mass within Greenland, and the ice sheet's sensitivity to atmospheric forcing. Proc. Natl Acad. Sci. USA 116, 1934-1939 (2019).

30. van As, D. et al. Reconstructing Greenland Ice Sheet meltwater discharge through the Watson River (1949-2017). Arct. Antarct. Alp. Res. 50, S100010 (2018)

31. Porter, C. et al. ArcticDEM https://doi.org/10.7910/DVN/OHHUKH (Harvard Dataverse, 2018)

Publisher's note: Springer Nature remains neutral with regard to jurisdictional claims in published maps and institutional affiliations.

(C) The Author(s), under exclusive licence to Springer Nature Limited 2019 


\section{METHODS}

Firn core and in situ GPR measurements. Firn cores were drilled at 100-m elevation intervals between $1,840 \mathrm{~m}$ and 2,350 $\mathrm{m}$ along the ACT-13 ground-penetrating radar transect (Extended Data Fig. 2, Extended Data Table 1), with two cores drilled at KAN_U approximately $3 \mathrm{~km}$ north of the main transect and two more cores at Dye-2, $40 \mathrm{~km}$ south of the main transect. Cores were logged for stratigraphy at $1 \mathrm{~cm}$ resolution and cut into $10-\mathrm{cm}$ intervals to record density. Using core sections with clean cuts consisting of purely refrozen ice, we measured the density of refrozen 'bubbly' ice in firn to be $873 \pm 25 \mathrm{~kg} \mathrm{~m}^{-3}$ (ref. ${ }^{5}$ ). Core data presented here are publicly available in the latest release of the NASA SumUp dataset ${ }^{32}$.

A Malå 800-MHz shielded GPR was used in situ to collect data in a $1 \mathrm{~km} \times 1 \mathrm{~km}$ grid at KAN_U adjacent to cores 1 and 2, in select tracks at Dye-2 near cores 5 and 6 , and along the main transect line adjacent to the remaining coring sites. The GPR data were resampled at a constant trace spacing of $1.5 \mathrm{~m}$. We applied a dewow filter to remove low-frequency artefacts and an exponential-gain filter to compensate for depth-dependent signal attenuation. We then processed the traces with a moving window to compute local variance in the GPR signal, which is considerably lower in thick refrozen ice than in porous firn ${ }^{5}$. We applied an adaptive linear-gain filter to eliminate residual depth attenuation that remained after data post-processing. We converted the radar's two-way travel time to depth using a correlation function that maximized the negative correlation between the core density and the local signal variance at core locations. We chose a cutoff for local signal variance to identify refrozen ice layers within the firn, in order to minimize both type-1 (commission) and type-2 (omission) errors compared to adjacent cores. The chosen cutoff of $5.0 \mathrm{~dB}$ in local relative variance of the GPR signal was sufficient to identify ice slabs $\geq 1 \mathrm{~m}$ thick with an average error of $-13.4 \%$ to $+3.2 \%$ compared to adjacent cores. Ice thickness estimates derived from this GPR technique should be considered as 'lower bound' estimates, only suitable for reliably identifying ice layers that are both thick and spatially continuous, consistent with the purpose of this study. Further details of GPR processing are available in Supplementary Information.

IceBridge AR. Data obtained with IceBridge AR $^{33}$ during 2010-2014 were acquired from the public FTP website (https://data.cresis.ku.edu/) of the Center for Remote Sensing of Ice Sheets. We filtered flight lines to cover the extent of Greenland's ice using the Greenland Ice Mapping Project ${ }^{34}$ land classification dataset. Because we are only interested in firn processes, we additionally subset the data to include only returns above the long-term equilibrium line altitude where past long-term average melt does not exceed long-term accumulation, and within the percolation area where melt exceeds $10 \%$ of accumulation in an average year as determined by the RCMs.

Raw IceBridge AR data were processed to improve surface selections and minimize surface selection artefacts caused by signal echoes and mismatches. To correct for the weakening of the IceBridge AR signal due to roll of the aircraft, a depth-dependent roll correction factor was applied to each flight line. In 2012, flight path curvature substituted aircraft roll because roll data were not provided (Supplementary Information, section S2.3).

Liquid water in or on the firn causes a bright reflection at the water's surface and a rapid attenuation of the signal to depth, making IceBridge AR samples unsuitable for detecting ice slabs beneath the water table. Radar lines were manually filtered to eliminate 113 surface lakes ${ }^{35}$ and regions containing visible subsurface aquifers.

The IceBridge AR data were exponentially depth-corrected in the top $50 \mathrm{~m}$ to provide a homogeneous signal strength by dividing with a best-fit exponential decay curve on each file and correcting for signal decay. Because flight lines from different years and instrument configurations provide different radar behaviours, exponential de-trending was performed independently on each flight line. We then normalized returns from each IceBridge AR flight line to have a mean value of 0 and a standard deviation of 1 , providing consistent return strengths throughout the dataset and minimizing inter-campaign variability of the returns.

We identified a signal threshold cutoff to differentiate weaker signals from relatively homogeneous ice from surrounding firn with stronger backscatter. We applied a simple noise filter to eliminate small-scale (1-2 pixels) noise from the images and then used a continuity filter to remove small disconnected groups of pixels from the image and leave only spatially continuous regions of pixels identified as ice slabs. We used a two-dimensional minimization search to validate the reference track '20130409_01_010_012' against the 800-MHz GPR line and chose a signal threshold and continuity cutoff that minimize type- 1 and -2 errors. A sensitivity threshold of -0.45 (in normalized decibels) and a continuity threshold of 350 pixels minimized the sum of type- 1 and type- 2 errors compared to ice identified in the GPR data (Supplementary Information Fig. 13). IceBridge AR traces with more than $16 \mathrm{~m}$ of ice in the top $20 \mathrm{~m}$ of firn were discarded to eliminate regions of bare ice to depth. The IceBridge AR data give estimates of ice content in the firn with an error rate of $-16 \%$ to $+5 \%$ compared to the GPR data. Combined with a GPR accuracy of $-13 \%$ to $+3 \%$ compared to the core data (previous section), we estimated the root-sum-squared error of the IceBridge AR data to be $-21 \%$ to $+6 \%$ accurate when identifying ice slabs $>1 \mathrm{~m}$ in the top $20 \mathrm{~m}$ of firn, compared to the 'truth' in firn cores drilled along the GPR surveys. Generally, IceBridge AR underestimates the total ice content compared with firn cores retrieved at the same location, primarily owing to its limited data resolution and quality. The IceBridge AR reference track was a straight flight line $\left(<1^{\circ}\right.$ aircraft roll) with relatively high data quality, but data from some IceBridge AR flight lines had low quality owing to aircraft roll, pitch or other factors, resulting in the data gaps shown in Fig. 2, where ice slabs may exist in the firn but are not identified (type- 2 omission errors). Excess melt calculations. We modified a previously defined relationship for the threshold between annual melt and snow accumulation ${ }^{18}$ to include rainwater, which affects firn in a similar manner to meltwater and is projected to increase across Greenland's accumulation area in a warming climate ${ }^{36}$. We calculate the amount of excess melt $M_{\mathrm{e}}\left(\right.$ in $\left.\mathrm{kg} \mathrm{m}^{-2}\right)$ as

$$
M_{\mathrm{e}}=\left\{\frac{M+R}{C}-\left[\left(\frac{h}{L} T_{\mathrm{f}}+\frac{\rho_{\mathrm{r}}-\rho_{\mathrm{c}}}{\rho_{\mathrm{c}}}\right)\left(1+\frac{\rho_{\mathrm{r}}-\rho_{\mathrm{c}}}{\rho_{\mathrm{c}}}\right)^{-1}\right]\right\} C
$$

where $M$, melt (in $\left.\mathrm{kg} \mathrm{m}^{-2}\right)$; $C$, accumulation $\left(\mathrm{kg} \mathrm{m}^{-2}\right) ; R$, rainwater $\left(\mathrm{kg} \mathrm{m}^{-2}\right) ; h$, heat capacity of ice $\left(\mathrm{J} \mathrm{K}^{-1} \mathrm{~kg}^{-1}\right)$; $L$, latent heat refreezing capacity of ice $\left(\mathrm{J} \mathrm{kg}^{-1}\right) ; T_{\mathrm{f}}$, temperature of underlying firn $\left({ }^{\circ} \mathrm{C}\right.$, positive below freezing; that is, $T_{\mathrm{f}}=20$ denotes a temperature of $-20^{\circ} \mathrm{C}$ ), derived from mean annual air temperature; $\rho_{\mathrm{r}}$, density of refrozen ice $\left(\mathrm{kg} \mathrm{m}^{-3}\right)$; and $\rho_{\mathrm{c}}$, density of fresh snow accumulation $\left(\mathrm{kg} \mathrm{m}^{-3}\right)$. We calculated $\rho_{\mathrm{c}}$ using a geographically based parameterization used in surface mass balance models ${ }^{37}$, and obtained accumulation density values of $300-380 \mathrm{~kg} \mathrm{~m}^{-3}$, a range consistent with independent observations ${ }^{32}$. We used $\rho_{\mathrm{r}}=873 \mathrm{~kg} \mathrm{~m}^{-3}$ for the density of refrozen ice, as found in firn cores ${ }^{5}$. Excess melt calculations are generally insensitive to reasonable variations in $\rho_{\mathrm{r}}$ and $\rho_{\mathrm{c}}$, consistent with previous reports ${ }^{18}$. In this work, excess melt is calculated on a 10 -year running mean (that is, mean values in 2001 were calculated from 1992-2001, inclusive) to compute decadal averages and to smooth inter-annual variability when considered for the formation of ice slabs. In the main text excess melt values are given in millimetres water equivalent, which is functionally equivalent to the unit of kilograms per square metre in Eq. (1).

Ice slab model simulations. We used three regional climate models ${ }^{1,2,38}$ forced by the ERA-Interim ${ }^{39}$ and $\mathrm{NCEPv}^{40}$ reanalysis datasets (Table 1) to determine the range of decadal excess melt volumes that have caused ice slabs to form within the firn, as identified by IceBridge AR data from 2010-2014. We used a subset of IceBridge flight lines that transect ice slab areas in straight 'downhill to uphill' (from the ice edge to the interior) orientations, where both the thick 'bottom' and the thin 'top' extents of ice slabs are identified (Supplementary Table 2). The range of 266-573 $\mathrm{mm}$ w.e. of mean annual excess melt during the full decade before the observations fits the observations of current ice slabs with good agreement between the models (Supplementary Information Fig. 16). Areas that averaged this amount of excess melt or more during the prior 'baseline' period before 1990 were masked out as being in the long-term ablation area, where porous firn would not exist in appreciable volume. Regions with enough annual accumulation to form perennial firn aquifers were masked out and not included in ice slab calculations.

We applied identical thresholds to RCMs forced at their boundaries by five GCMs $^{41-45}$ under the RCP 4.5 and RCP 8.5 climate scenarios ${ }^{46}$ (Table 1). For the HIRHAM 5 RCM, no data were available to compute a pre-1990 baseline period, and 1990-1999 was used instead with ice slabs growing after the year 2000, which may bias the results to lower values for that particular RCM. GCM time periods using GCM historical forcing were combined with each respective 21st-century forcing to form continuous datasets.

Runoff calculations. Inter-annual variability in melt and accumulation are high in Greenland, with some years demonstrating exceptional melt and others showing relatively low levels of melt and runoff. When excess melt is negative, it represents the amount of pore volume (absence of melt) added at a given location. When the model estimates that an ice slab has formed on/near the ice-sheet surface, pore volume added atop the slab in subsequent years is tallied on an annual basis from RCM accumulation and melt results. Surface melt in future years is expected to saturate accumulated pore volume and overwhelm near-surface firn pore space and cold content before further runoff occurs. Melt that filled near-surface pore space but did not melt out further adds to the ice slabs and grows them thicker, consistent with Extended Data Fig. 1b. Runoff from the top of ice slabs is tallied on an annual basis and is presented in Fig. 3 as a running sum total. Means and trends are outlined in Table 1. Runoff estimates from the RCMs without the effects of ice slabs were estimated by measuring the runoff zone (maximum area in which runoff has occurred at least once) before the formation of ice slabs and totalling the future runoff from regions higher on the ice sheet where runoff did not previously occur.

\section{Data and code availability}

Firn cores presented in Extended Data Fig. 1 are available in the 2018 release of Greenland's SumUp dataset ${ }^{32}$. Post-processed GPR and IceBridge AR transects, 
shapefiles and CSV-summaries are publicly available in Figshare project 'Greenland Ice Slabs Data' at https://doi.org/10.6084/m9.figshare.8309777. Codes for postprocessing core, GPR, IceBridge AR and RCM data are available at https://github. com/mmacferrin/Greenland_Ice_Slabs. RCM outputs are available from the respective online data repositories for each model and/or upon request from the authors. Greenland boundary outlines used in all maps are available from the Natural Earth open-access GIS repository at https:/www.naturalearthdata.com/ downloads/.

32. Montgomery, L., Koenig, L. \& Alexander, P. The SUMup dataset: compiled measurements of surface mass balance components over ice sheets and sea ice with preliminary analysis over Greenland. Earth Syst. Sci. Data 10, 1959-1985 (2018).

33. Leuschen, C. IceBridge Accumulation Radar L1B Geolocated Radar Echo Strength Profiles (National Snow and Ice Data Center, 2014).

34. Howat, I. M., Negrete, A. \& Smith, B. E. The Greenland Ice Mapping Project (GIMP) land classification and surface elevation data sets. Cryosphere $\mathbf{8}$, 1509-1518 (2014).

35. Koenig, L. S. et al. Wintertime storage of water in buried supraglacial lakes across the Greenland Ice Sheet. Cryosphere 9, 1333-1342 (2015).

36. Doyle, S. H. et al. Amplified melt and flow of the Greenland ice sheet driven by late-summer cyclonic rainfall. Nat. Geosci. 8, 647-653 (2015).

37. Langen, P. L., Fausto, R. S., Vandecrux, B., Mottram, R. H. \& Box, J. E. Liquid water flow and retention on the Greenland Ice Sheet in the regional climate model HIRHAM5: local and large-scale impacts. Front. Earth Sci. 4, 110 (2017).

38. Christensen, O. et al. The HIRHAM Regional Climate Model Version 5 (Beta). Technical Report No. 06-17 (Danish Meteorological Institute, 2007).

39. Dee, D. P. et al. The ERA-Interim reanalysis: configuration and performance of the data assimilation system. Q. J. R. Meteorol. Soc. 137, 553-597 (2011).

40. Kalnay, E. et al. The NCEP/NCAR 40-year reanalysis project. Bull. Am. Meteorol. Soc. 77, 437-471 (1996).

41. Hazeleger, W. et al. EC-Earth: a seamless Earth-system prediction approach in action. Bull. Am. Meteorol. Soc. 91, 1357-1364 (2010).

42. Chylek, P., Li, J., Dubey, M. K., Wang, M. \& Lesins, G. Observed and model simulated 20th century Arctic temperature variability: Canadian Earth System Model CanESM2. Atmos. Chem. Phys. Discuss. 2011, 22893-22907 (2011)
43. Watanabe, M. et al. Improved climate simulation by MIROC5: mean states, variability, and climate sensitivity. J. Clim. 23, 6312-6335 (2010).

44. Bentsen, M. et al. The Norwegian Earth System Model, NorESM1-M - Part 1: description and basic evaluation of the physical climate. Geosci. Model Dev. 6, 687-720 (2013)

45. Collins, W. J. et al. Evaluation of the HadGEM2 Model. Technical Note No. 74 (Met Office, Hadley Centre, 2008).

46. IPCC. Climate Change 2013: The Physical Science Basis (eds Stocker, T. F. et al.) (Cambridge Univ. Press, 2013).

Acknowledgements We acknowledge National Aeronautics and Space Administration (NASA) awards NNX10AR76G and NNX15AC62G for funding most of the work, including field campaigns. This work was also supported by the Retain project, funded by the Danish Council for Independent Research (grant number 4002-00234). Research leading to these results received funding from the European Research Council under the European Union's Seventh Framework Programme (FP7/2007-2013)/ERC grant agreement 610055 as part of the ice2ice project. We thank the field team members for their contributions to field data collection in 2012-2017.

Author contributions M. MacFerrin conceived the study question, processed the core, GPR and IceBridge AR data, post-processed the RCM output data and is the primary author of the manuscript and supplement. All authors contributed to the manuscript text, analyses, figures and revisions. M. MacFerrin, H.M., and D.v.A. planned, organized and undertook field campaigns dedicated to the data presented in this paper. C.C., C.M.S., B.V. and A.H. collected, interpreted and/ or plotted field data. P.L.L., R.M., X.F. and M.R.V.d.B. provided regional climate model outputs and assisted with their results and interpretations. W.T.P. helped formulate and interpret the excess melt model. M. Moussavi performed remotesensing validation of runoff over ice slabs. W.A. supervised and oversaw the direction and formulation of the manuscript and project.

Competing interests The authors declare no competing interests.

Additional information

Supplementary information is available for this paper at https://doi.org/ 10.1038/s41586-019-1550-3.

Correspondence and requests for materials should be addressed to M.M. Reprints and permissions information is available at http://www.nature.com/ reprints. 

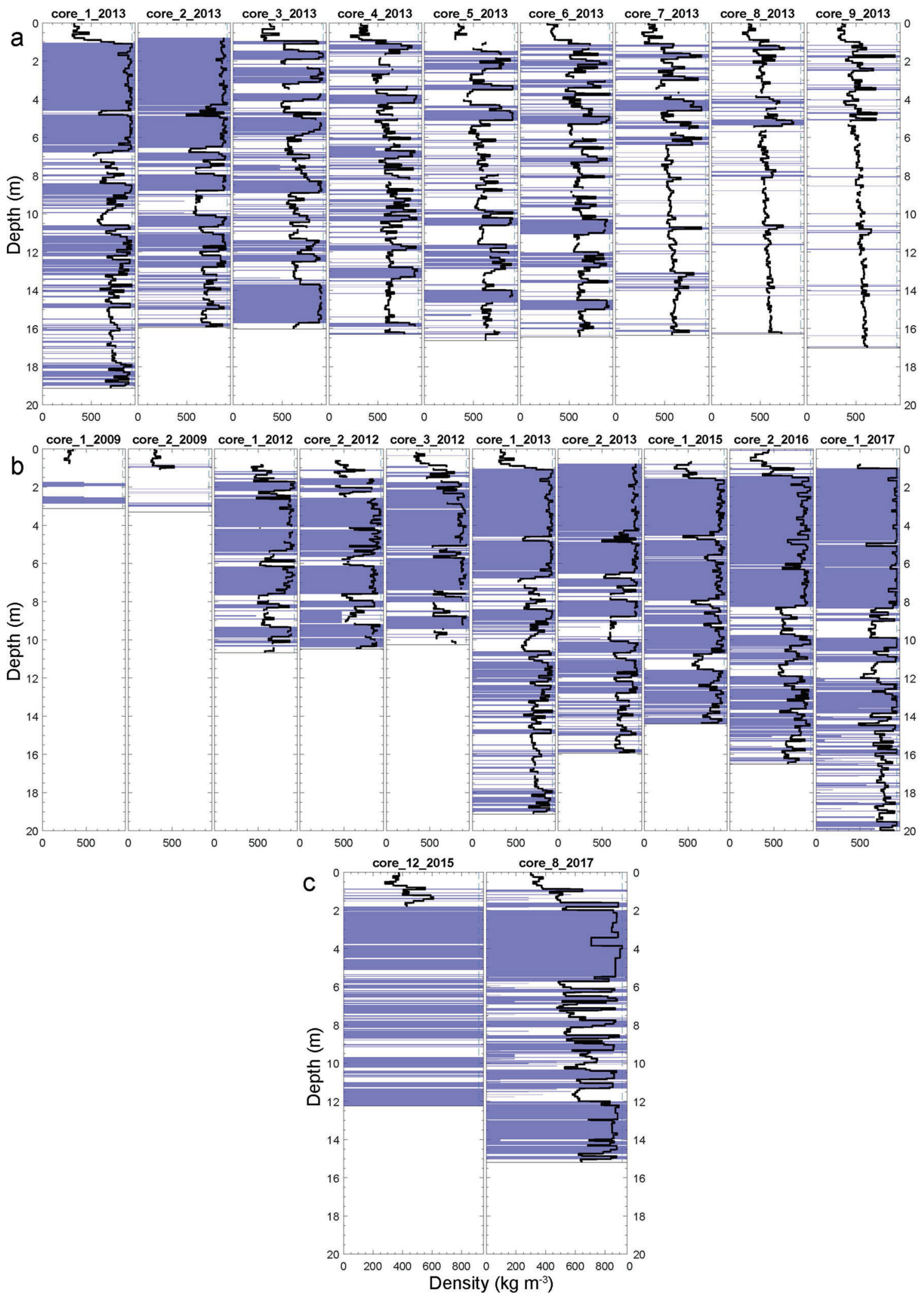

Extended Data Fig. 1 | Firn core density profiles. Firn density is plotted in black with ice layers indicated in blue. a, Firn cores drilled during the ACT-13 campaign ${ }^{5}$. b, A time series of firn core measurements at the
KAN_U field site; data obtained in 2009-2017. c, Firn cores from the BAB_U field site, $40 \mathrm{~km}$ southeast of KAN_U, measured in 2015 and 2017. 
LETTER RESEARCH

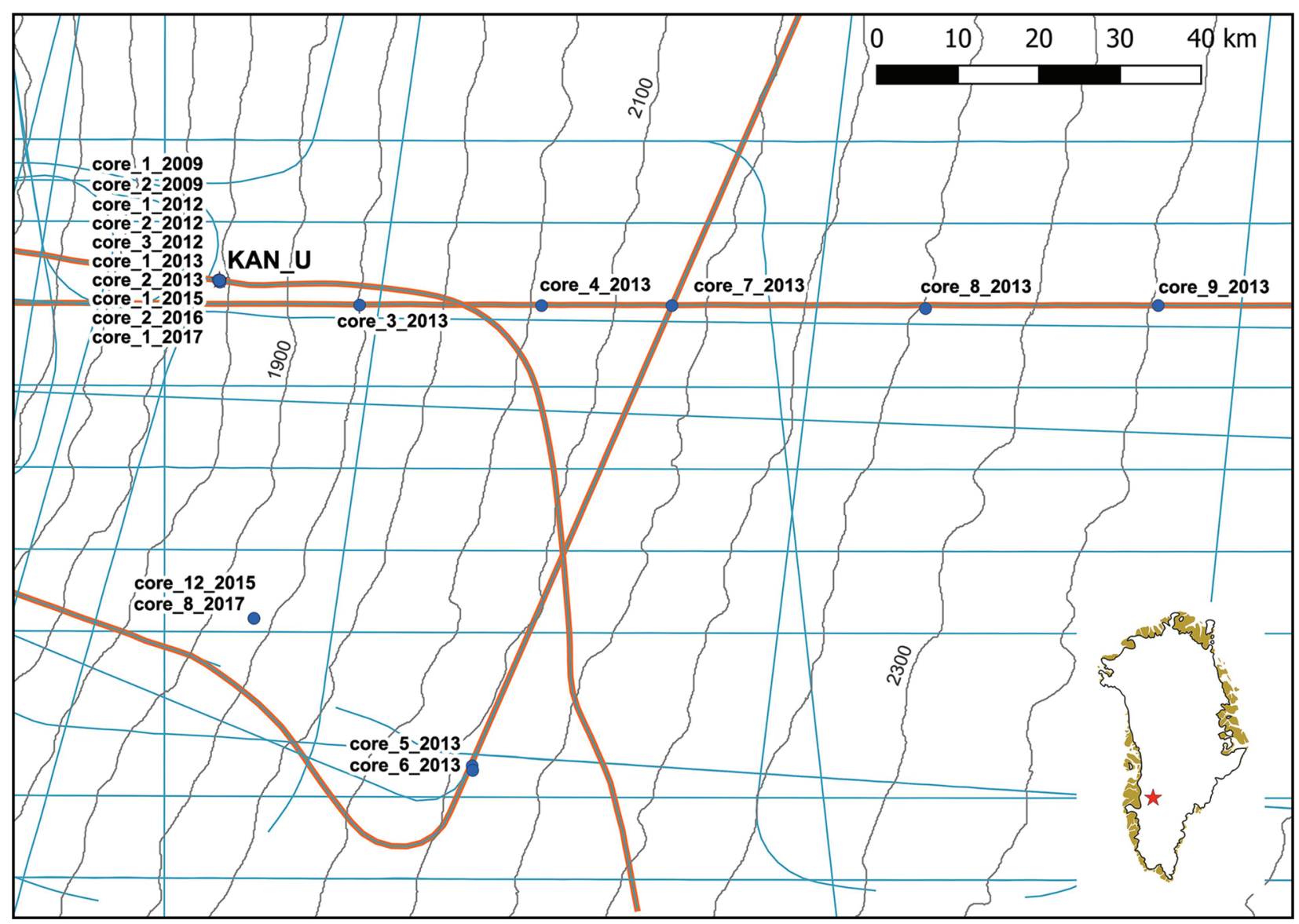

Extended Data Fig. 2 | Map of core locations. IceBridge flight lines are shown in light blue and 50-m-elevation contours in grey. KAN_U, at an elevation of $1,840 \mathrm{~m}$, is identified on the left. IceBridge flight lines that overlap core locations are highlighted in orange. 


\section{RESEARCH LETTER}

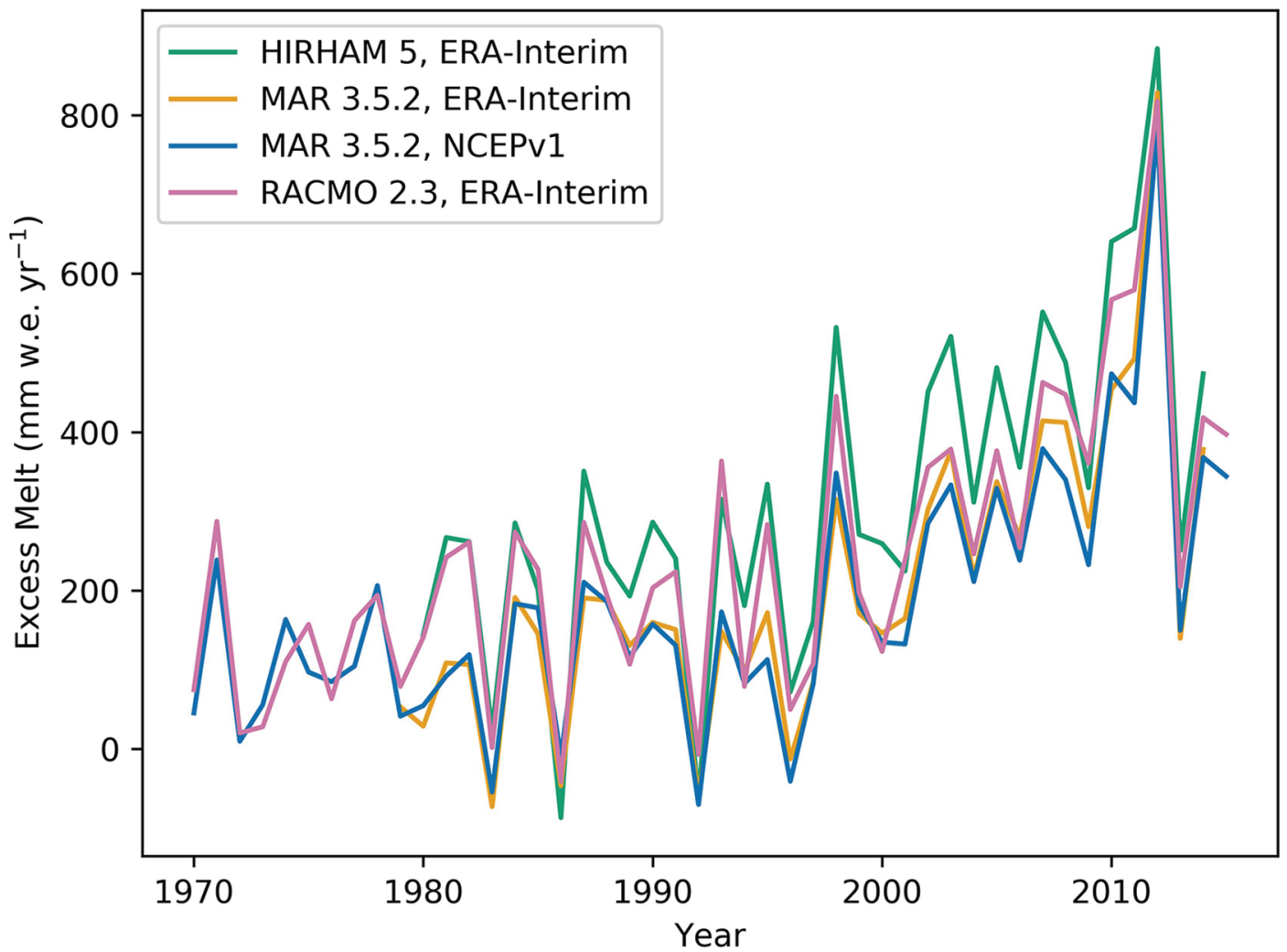

Extended Data Fig. 3 | RCM calculations of excess melt in pixels in which ice slabs are detected by IceBridge AR data. 
a

\begin{tabular}{|c|c|c|c|c|c|c|c|c|}
\hline \multirow[b]{2}{*}{ Dataset: } & \multicolumn{8}{|c|}{ Drainage Basin: } \\
\hline & B1 & B2 & B3 & B4 & B5 & B6 & B7 & B8 \\
\hline \multirow{2}{*}{ IceBridge Flight Lines } & 16.36 & 11.24 & 1.18 & 0.00 & 0.00 & 15.22 & 9.70 & 15.72 \\
\hline & $1120 \pm 150$ & $1072 \pm 149$ & $1573 \pm 144$ & & & $1773 \pm 106$ & $1591 \pm 105$ & $1358 \pm 188$ \\
\hline \multirow{2}{*}{ HIRHAM, ERA-Int } & 10.67 & 13.04 & 3.53 & 0.16 & 1.31 & 13.80 & 5.56 & 8.87 \\
\hline & $1167 \pm 113$ & $1160 \pm 147$ & $1583 \pm 212$ & $1595 \pm 121$ & $1913 \pm 59$ & $1733 \pm 098$ & $1567 \pm 084$ & $1390 \pm 179$ \\
\hline \multirow{2}{*}{ MAR, ERA-Int } & 18.00 & 7.88 & 5.67 & 0.02 & 1.04 & 15.29 & 7.07 & 11.38 \\
\hline & $1051 \pm 133$ & $1000 \pm 228$ & $1535 \pm 274$ & $1943 \pm 207$ & $2132 \pm 45$ & $1869 \pm 159$ & $1538 \pm 274$ & $1224 \pm 168$ \\
\hline \multirow{2}{*}{ MAR, NCEPV1 } & 15.06 & 5.26 & 5.81 & 0.00 & 0.52 & 12.50 & 5.28 & 9.16 \\
\hline & $1064 \pm 121$ & $1004 \pm 227$ & $1551 \pm 215$ & & $2098 \pm 41$ & $1829 \pm 152$ & $1531 \pm 110$ & $1238 \pm 189$ \\
\hline \multirow{2}{*}{ RACMO, ERA-Int } & 16.25 & 11.56 & 4.96 & 0.38 & 0.65 & 16.82 & 7.18 & 8.60 \\
\hline & $1082 \pm 138$ & $1046 \pm 167$ & $1654 \pm 221$ & $1862 \pm 138$ & $2074 \pm 93$ & $1845 \pm 140$ & $1596 \pm 106$ & $1324 \pm 265$ \\
\hline
\end{tabular}

b

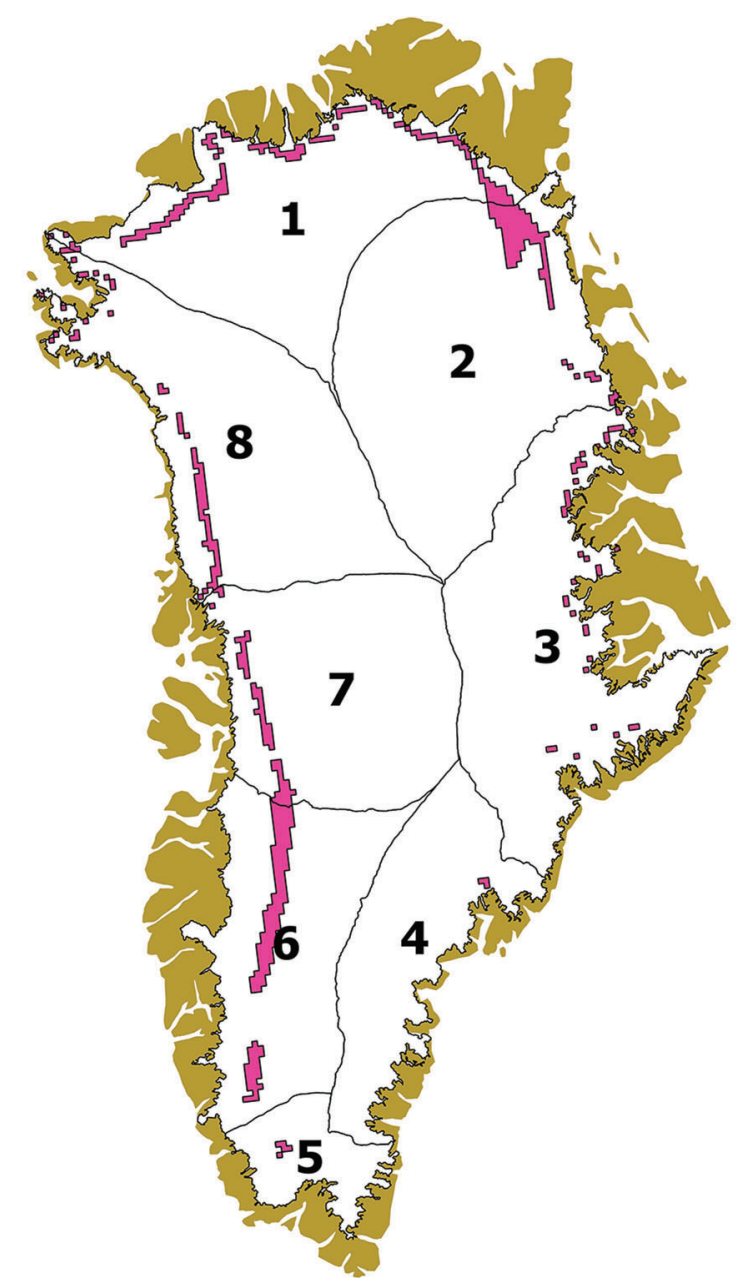

Extended Data Fig. 4 Simulated ice slabs in Greenland drainage basins. a, Area $\left(\times 10^{3} \mathrm{~km}^{2}\right.$; top) and mean elevation (in metres, \pm 1 s.d.; bottom) of ice slabs, as detected by IceBridge AR and simulated by RCMs, around 2014. b, Ice slabs simulated using RACMO ERA-Int 2014 model results in each drainage basin. 


\section{RESEARCH LETTER}

\section{Extended Data Table 1 | Metadata of firn cores}

\begin{tabular}{lllllll}
\hline Core Name & Site Name & $\begin{array}{l}\text { Date } \\
\text { yyyy/mm/dd }\end{array}$ & Lat $\left(^{\circ}\right.$ ) & Lon $\left(^{\circ}\right)$ & Elev $(\mathbf{m})$ & Depth $(\mathrm{m})$ \\
\hline core_1_2013 & KAN_U & $2013 / 04 / 27$ & 67.00025 & 47.02263 & 1840 & 19.12 \\
core_2_2013 & KAN_U & $2013 / 04 / 28$ & 66.99837 & 47.02213 & 1840 & 15.94 \\
core_3_2013 & (transect) & $2013 / 04 / 30$ & 66.97795 & 46.62850 & 1950 & 16.03 \\
core_4_2013 & (transect) & $2013 / 05 / 03$ & 66.98218 & 46.11945 & 2060 & 16.30 \\
core_5_2013 & Dye-2 & $2013 / 05 / 05$ & 66.47758 & 46.28472 & 2119 & 16.64 \\
core_6_2013 & Dye-2 & $2013 / 05 / 05$ & 66.47260 & 46.28298 & 2119 & 16.45 \\
core_7_2013 & (transect) & $2013 / 05 / 15$ & 66.98458 & 45.75465 & 2142 & 16.35 \\
core_8_2013 & (transect) & $2013 / 05 / 13$ & 66.98322 & 45.04490 & 2266 & 16.28 \\
core_9_2013 & EKT & $2013 / 05 / 19$ & 66.98528 & 44.39360 & 2361 & 17.01 \\
core_1_2009 & KAN_U & $2009 / 07 / 01$ & 67.00025 & 47.02130 & 1840 & 3.13 \\
core_2_2009 & KAN_U & $2009 / 07 / 01$ & 67.00025 & 47.02130 & 1840 & 3.31 \\
core_1_2012 & KAN_U & $2012 / 04 / 29$ & 67.00025 & 47.02130 & 1840 & 10.50 \\
core_2_2012 & KAN_U & $2012 / 04 / 30$ & 67.00025 & 47.02138 & 1840 & 10.47 \\
core_3_2012 & KAN_U & $2012 / 05 / 02$ & 66.99825 & 47.02083 & 1840 & 10.00 \\
core_1_2015 & KAN_U & $2015 / 05 / 05$ & 67.00042 & 47.02472 & 1840 & 14.4 \\
core_2_2016 & KAN_U & $2016 / 04 / 28$ & 67.00038 & 47.02615 & 1840 & 16.51 \\
core_1_2017 & KAN_U & $2017 / 04 / 28$ & 67.00025 & 47.02263 & 1840 & 23.27 \\
core_12_2015 & BAB_U & $2015 / 05 / 21$ & 66.63205 & 46.89497 & 1927 & 12.24 \\
core_8_2017 & BAB_U & $2017 / 05 / 13$ & 66.63205 & 46.89497 & 1927 & 15.19
\end{tabular}

Lat, latitude; Lon, longitude; Elev, elevation. 